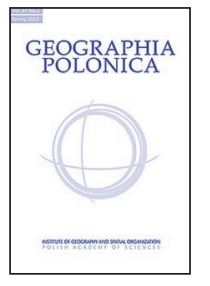

\title{
ESTIMATING THE SHORT-TERM ECONOMIC IMPACT OF COVID-19 PANDEMIC: A REGIONAL PERSPECTIVE
}

\author{
Zizi Goschin $^{1,2}$ (D) Daniela-Luminita Constantin ${ }^{1}$ (D) \\ ${ }^{1}$ Bucharest University of Economic Studies \\ Piata Romana 6, sector 1, RO-010374 Bucharest: Romania \\ ${ }^{2}$ Institute of National Economy \\ Calea 13 Septembrie 13, sector 5, RO-050731 Bucharest: Romania \\ e-mails: zizi.goschin@csie.ase.ro • daniela.constantin@amp.ase.ro (corresponding author)
}

\begin{abstract}
Given the economic crisis related to the current COVID-19 pandemic, decision makers need to better understand how to effectively allocate their limited resources to support the most severely affected regions. In this context our research seeks to identify the regions that are economically vulnerable, as well as those that are more resilient, using information on the industries negatively impacted by travel restrictions and social distancing measures. With this aim in view, we propose a vulnerability index calculated using regions' location coefficients by activity and the forecasted decline of these activities at national level and test it for the Romanian economy. We argue that regional specialisation itself is not the source of the current problems, but the high dependence of many regional economies on economic activities directly affected by measures designed to mitigate the epidemic impact is the root cause of future economic decline.
\end{abstract}

\section{Key words}

COVID-19 pandemic $\bullet$ economic effects $\cdot$ regional specialisation $\bullet$ vulnerability index $・$ Romania

\section{Introduction}

As the world finds itself on an unexplored territory, being confronted with the first global pandemic of the 21st century, we believe that the economic science research can offer crucial information on the possible effects of the SARS-CoV-2 (COVID-19) pandemic, given the measures undertaken in order to diminish its spreading, with large economic consequences. The scientific community has the important tasks to correctly define the generated challenges, to propose proper inquiry methodologies and to offer evidence-based reports of scientific results, followed by their communication to all relevant actors: academic community, policy-makers and interested public (Gombos et al., 2020).

The vast majority of countries have imposed strict policies for the disease prevention 
and active cases administration, trying to support their national sanitary systems' efforts, so as to avoid a possible collapse. The adopted measures envisaged the temporary closure of a big number of businesses, the severe restrictions on international travels and limitations in local mobility, which entailed a drop of production, investments, household incomes as well as of trade, especially the international one. Even if the amplitude of the negative effects and their short- and medium-term implications cannot be estimated with high accuracy, a significant economic contraction - generalised in a globalised world - is expected. According to the World Bank estimations, the economic decline will exceed four percent in Europe and Central Asia (World Bank, 2020).

The negative effects of production decrease as a result of the measures aimed at preventing the epidemic spreading have been subsequently amplified by the decline of domestic consumption and investments, making it difficult the economic recovery without large-scale governmental support measures. The economic effects of pandemic vary between countries and between regions as well, depending not only upon the severity of economic contraction but also on the effectiveness of the measures conceived for counteracting these effects'.

COVID-19 has a strong regional impact, requiring differentiated responses in terms of governance and policy measures. The regional and local impact of crisis has been extremely asymmetric (OECD, 2020). The speed and scale of spread of the epidemic, the severity of the negative effects generated, the disturbance of society and economy differ significantly from region

\footnotetext{
1 In terms of economic growth theory, the situation generated by the COVID-19 pandemic can be described through the lens of the "Real Business Cycle" models - based on the seminal work of Kydland and Prescott (1982) - which highlight the role of real shocks in propelling business fluctuations. After the initial emphasis on technology shocks, derived theories concentrated on other shocks - different from the technology ones - as well (Rebelo, 2005).
}

to region, requiring a response adapted to local characteristics.

Undoubtedly, regional science can bring new perspectives on the economic effects of this crisis and can provide valuable information for a better understanding of the situation - which might reappear in the future, creating favourable conditions for a more resilient society. In Romania too, the regional distribution of infection cases, but especially the economic implications of social distancing measures taken in the context of emergency ordinances, have an unequal regional distribution. The International Monetary Fund (IMF) estimated for Romania's economy a decrease of 5\% in 2020, followed by recovery and economic growth of $3.9 \%$ in 2021 . The study of the National Institute of Statistics (NIS) on the assessment of the impact of COVID-19 on the economic environment in March and April 2020 revealed the concerns of economic agents, the perception of managers on the perspective of evolution of their companies getting substantially worse: thus, the share of those foreseeing the reduction of the company's activity by over 25\% increased from 33.3\% in March to $45.0 \%$ in April (NIS, 2020b). These expected developments at national level will certainly show great variation at regional and local level. Even areas with low incidence of disease, with few or no serious cases requiring the local medical system at full capacity, are severely affected by the reduction in economic activity, especially if sectors such as hotels and restaurants, transportation, construction, etc. have a high share in the local economy. As in the case of "classical" crises, the economic shock caused by the pandemic seems to be closely related to the sectoral structure of local economies, the source of problems not being specialisation itself, but the high dependence on activity sectors directly affected by strict health crisis management policies. Similar positions have resulted from research dedicated to the 2007-2008 economic recession, for example the study by Cuadrado-Roura and Maroto (2016), which supports the idea 
that not every type of specialisation attenuates economic resilience, but certain activities (like mining, construction and parts of the low-tech manufacturing sector) are more vulnerable to economic shocks than others, such as agriculture and most services. As a consequence, regions that are highly specialised in such sensitive sectors are likely to suffer more severe hits during economic crises (De Groot et al., 2011).

Based on these considerations and taking into account that governments and communities in the affected regions need to better understand where their limited resources can be most effectively allocated (but also where their greatest needs are), our research seeks to identify the areas which are the most economically vulnerable, as well as those most pandemic-resistant, using information on the activities most affected by travel restrictions and by the imposing of social distancing measures, and areas with high proportion of temporary or part-time employment. To this end we propose a vulnerability index calculated by means of the regions' location coefficients by activity and the forecasted decline of these activities at national level. Next, for a deeper image of the distribution of the vulnerability index, the spatial dependence among its county level values is tested, using the standard method for identifying spatial autocorrelation, namely the Moran's I indicator. The empirical analysis is performed using the available data in the case of Romania.

The conclusions and recommendations resulted from our research can support the elaboration of regional policies to combat the negative effects produced by the COVID-19 epidemic. In this context, the appropriate economic specialisation, which makes good use of local economic resources and increases economic efficiency, can be a way of stimulating economic growth and reducing development disparities between regions. The exposed issue is a very important and timely one, given the fact that the large variations in economic specialisation can fuel growing regional inequalities, which can be counteracted by regional strategies and policies of harmonious, balanced development, while decision-makers would benefit from a better understanding of how economic specialisation influences this process, increasing vulnerabilities in times of crisis.

\section{An inquiry into the literature regarding the regional dimension of the COVID-19 - related economic crisis}

From the very start of its first wave, the sanitary crisis generated by the COVID-19 pandemic has been accompanied by an economic and social crisis with severe effects at international, national and regional scale. The recession prompted by the pandemic at all these levels has induced important disruptions in the economic and social equilibria, reflected by the changes in unemployment rates, wages, transportation, global supply chains, climate and environment, etc. (AISR, 2020; Mazza \& Mavri, 2020).

Moreover, according to a caveat in the examination of global pandemic shocks that can be applied to the COVID-19 pandemic as well, "such a global crisis usually consists of several sub-shocks (i.e., immediate economic recession caused by reduced mobility and a further shrinkage caused by declining demand in different parts of the world" (Gong et al., 2020: 509).

The analysis of the first wave indicates an unevenly distributed geographical impact of the current economic crisis, with higher variations within countries compared to the variations between countries (Bailey et al., 2020; Ortega-Argilés, 2020; KPMG, 2020; McCoy, 2020). This is the result of significant differences in the regional, local responses to crisis despite the global nature of the pandemic shock. The spatial heterogeneity within countries has multiple sources, such as: regions' economic specialisation, human capital stocks, the division between essential and non-essential businesses and the length of lockdown, the seasonal nature 
of various businesses (e.g., seaside tourism), trade orientation, mobility and isolation compliance, etc. (Kitsos, 2020a; Kitsos, 2020b; Niembo \& Calá, 2020; Gombos, 2020; Boumahdi et al., 2020). A serious concern envisages the people that live in disadvantaged areas and conditions, a deepening of intra- and inter-regional inequalities being expected as a result of the COVID-19-generated economic crisis (Ortega-Argilés, 2020; Williamson et al., 2020).

In the last decades the capacity of regional systems to recover from the shocks to which they were exposed has been analysed in terms of regional resilience, broadly defined as "the ability of a region / community to anticipate threats, to reduce their impact through preventive action, to respond appropriately when threats materialize and subsequently recover" (Dabson et al., 2012: 6). Regional resilience is seen as a "placesensitive, multi-layered and multi-scalar, conflict-ridden and highly contingent process", the nature of shocks being considered as "one important impact factor on regional resilience" (Gong et al., 2020: 597). Initially, the resilience of a region is determined by the magnitude and severity of shocks and the ability to overcome them, depending on its resources and inherent vulnerabilities.

Vulnerability is a concept associated with resilience, which highlights the susceptibility and exposure to disturbances of the regional system or its components as a result of the manifestation of harmful effects of external shocks - economic, political, environmental, etc. (Hudec et al., 2017; Seelinger \& Turok, 2013). While exposure is considered a relational attribute, vulnerability is an attribute of the system itself, which is relevant when exposed to external shock (Gallopin, 2006). Vulnerability refers to structural changes in the system caused from the outside and involves changes in the parameters that define its stability.

The manifestation of the current crisis has attracted a lot of interest in analysing the spatial differences in vulnerability to crisis in many countries. For this paper we have selected a couple of relevant examples from the perspective of our own approach.

Thus, Irving (2020) has proposed a pandemic vulnerability index in order to reveal the Australian towns which are the most vulnerable and resilient to COVID-19 pandemic in economic terms. To this end he has employed "metrics of public-facing industries affected by travel restrictions as well as those with large proportion of their workforce in temporary or part-time positions" (Irving, 2020: 1).

In Romania a municipality ranking has been established based on their resilience to crisis coming from the capacity to attract money to local budgets, with a particular emphasis on EU funding (UrbanizeHub, 2020). In addition, Volintiru (2020) points to the location of economic activities and local networks as a key factor able to preserve cities' economic dynamics above the national average.

At regional level Niembro and Calá (2020) have developed an index of territorial impact of COVID-19 crisis in the first pandemic wave in Argentina by means of two elements, namely the regional production structure (expressed in terms of formal private employment) and the so-called 'operational level' of each economic activity, considering that the restrictions were imposed at sectoral level, without particular regional criteria. The results show a highly heterogenous impact, influenced by the regional specialisation and productive diversity. For the next waves, when a flexibilization of the quarantine measures at both sectoral and territorial level is expected, the authors have in view more complex methodologies, which will consider, besides the regional economic structure, a wider range of characteristics such as regions' size, population density, number, frequency and speed of new cases spreading, mobility indexes, isolation compliance, etc.

In the same register, Kitsos (2020b) has addressed the case of the United Kingdom: his research focuses on the economic activities affected by the lockdown and aims to explore the variation of the crisis impact and resilience performance at regional level. By mapping the 
share of employment in these activities, combined with the share of working age residents that claim unemployment benefits, it was possible to identify the places with significant concentrations of workers that currently do not work. The results indicate a high diversity of the expected impact of crisis at local level and raise the question of the response capacity of each place, accompanied by the need of differentiated support measures.

In Austria Bachtrögler et al. (2020) have performed an exploratory analysis in order to assess the regional differences in economic vulnerability to COVID-19 crisis using data at Nomenclature of Economic Activities NACE-2 level for the sectoral structure. Depending on their vulnerability the economic activities have been classified using a fivelevel scale, from 'not affected' to 'very strong affected'. The economic activities are defined as strongly or very strongly affected "if they are currently unable to operate or can only operate to a very limited extent due to the measures taken and if it is (not) likely that they will be able to make up for the business they have lost at a later date" (Bachtrögler et al., 2020: 1). Compared to other studies focused on the regional dimension of the pandemicrelated economic crisis, this one is enriched with the influence of the demand-side restrictions generated by the decline in exports, the change in the private households' consumption behaviour and the supply-side restrictions resulted from the delays, interruptions in the supply chains. The results indicate a high negative economic impact in all Austrian regions as a consequence of the fact that in each region almost two thirds of employees work in sectors which are strongly and very strongly affected. Therefore, despite the significant economic differences in regional economic specialisation, the advantages and disadvantages displayed by the regional composition with regard to the vulnerability to crisis cancel each other to a quite large extent (Bachtrögler et al., 2020).

Apart from one-country-focused research, studies with a wide geographical coverage have been also undertaken. For example, the European Bank for Reconstruction and Development (EBRD) has provided a report entitled "From Shock to Recovery", which covers all EBRD regions (i.e., countries of operation in South-East Europe, Central Europe ad Baltic Countries, Eastern Europe and the Caucasus and Central Asia). The analysis of economic vulnerability has underlined as main factors of influence the structure of production, the share of employees on permanent contracts or working in the informal economy and governments' ability to provide relief. It draws the attention to the relation between the speed of recovery and lockdowns duration and argues that if the mass layoffs during containment are avoided the recovery will be faster, while the economic impact will be much deeper if lockdowns are applied for larger periods (EBRD, 2020a).

Based on the assessments provided by the empirical, exploratory inquiries, many debates have dealt with the policy measures aiming to cope with the economic and social disruptions provoked by the COVID-19 pandemic. They point to the increasing importance of the place-based policies, suggesting a rational combination between economic and spatial restructuring measures. A particular emphasis is put on "the timing of policy responses" that might have a "substantial effect" on the uneven territorial distribution of the pandemic crisis (Ortega-Argilés, 2020: 1). Thus, timely responses have to be offered to 'hot' topics regarding small and medium enterprises, tourism, cities, rural development, health-care infrastructure, multi-level governance, robustness of vertical and horizontal coordination mechanisms, etc. There are also discussions about new development models, which reconsider the spatial industrial organisation of the value chains and re-open the interest in local production systems (EC, 2020; Bailey et al., 2020; Stiglitz, 2020; Ivanov \& Dolgni, 2020), pinpoint the opportunities offered by 'the fourth industrial revolution' (De Propris \& Bailey, 2020) and shed new light on knowledge production and climate change challenges (Benett, 2020; Ortega-Argilés, 2020). 
These findings, resulted from the selected methodological approaches, empirical analyses and suggested policies have laid the foundations for the case study below, which concentrate on the short-term economic impact of the COVID-19 at regional level in Romania.

\section{Method and data}

In order to estimate the degree of local vulnerability to the negative economic effects of the COVID crisis we developed a new method that combines own calculations on each region's dependence on the most severely affected activities with the information provided by the National Strategy and Forecast Commission on the foreseeable short-term contraction of these activities.

The sectoral structure of the regional economies will be investigated with the localisation coefficient (Florence, 1939), also known as the Hoover-Balassa coefficient. It is a simple indicator, able to capture the position of each economic activity in the economy of a region, providing a realistic estimate on region's dependence, hence on region's vulnerability to the decline of that activity. The localisation coefficient of activity $j$ in region $i$ can be calculated starting either from the concentration rate $g_{i j}^{C}$ or the specialisation rate $g_{i j}^{S}$, as follows:

$$
\begin{aligned}
& L Q_{i j}=\frac{E_{i j} / E_{j}}{E_{i} / E}=\frac{E_{i j} / E_{i}}{E_{j} / E} \Leftrightarrow \\
\Leftrightarrow \quad L Q_{i j} & =\frac{g_{i j}^{C}}{E_{i} / E}=\frac{g_{i j}^{S}}{E_{j} / E} \\
g_{i j}^{S}= & \frac{E_{i j}}{\sum_{j=1}^{m} E_{i j}}=\frac{E_{i j}}{E_{i}}
\end{aligned}
$$

where:

$\mathrm{g}_{i j}^{C}$ - the concentration rate, computed as the share of region $i$ in the economic activity $j$,

$g_{i j}^{S}$-specialisation rate, representing the share of the economic activity $j$ in the total employed population of region $i$,
$\mathrm{E}_{i j}$ - the population employed in activity $j$ relative to total employment in region $i$,

$E_{j}$ - total employment in the economic activity $j$ for the whole national economy,

$E_{i}$ - total employed population or gross value added in region $i$,

E - total employed population at national level

i - region,

j - economic activity.

The magnitude of the localisation coefficient is interpreted as follows:

- $\mathrm{LQ}_{i j}>1$ indicates that economic activity $j$ holds an important position in the economy of region $i$, having a higher than average share (at national level)

- $\mathrm{LQ}_{i j}<1$ means that economic activity $j$ is underrepresented in the economy of region $i$, having a lower share than the national average of activity $j$.

For the computation of the localisation coefficients, we have used the official statistics on the civilian employment by activity at the NACE-2 level, by development region and county (NIS, 2020a). The time span was from 2008 to 2018 (the latest statistics available at territorial level).

The variations in the coefficients level are also influenced by the degree of data disaggregation by economic activity. The simplicity of the localisation coefficients makes them useful tools in the initial research stages. Based on the results regarding the localisation coefficients by county and by economic activity, the next step has been the calculation of the index of economic vulnerability to the current crisis caused by the measures aimed at mitigating the epidemic impact. This vulnerability index is built by combining the answers to the following two questions:

1. What is the contraction forecasted for the activities most affected by the crisis?

2. What is the importance of each of these activities in the region's economy?

To answer the first question we have employed the forecast provided by the National Commission for Strategy and Forecasting (NCSF) via "The current context of the Romanian economy and the impact 
of coronavirus on the main macroeconomic indicators" Report (NCSF, 2020), while for the second aspect we have calculated the localisation coefficients according to formula (1), for each economic activity, each county (NUTS3) and each development region (NUTS2).

Finally, we have combined the two criteria into a synthetic indicator of economic vulnerability to the COVID-19 crisis by calculating a weighted arithmetic mean according to the following formula:

$$
V_{i}=\frac{\sum_{j=1}^{k} L_{i j} \cdot\left(D_{j} / \sum_{j} D_{j}\right)}{100}
$$

where:

$V_{i}$ - the vulnerability index,

$\mathrm{LQ}_{i j}$ - the localisation coefficient of activity $j$ in region $i$,

$D_{j}$ - the decline forecast for activity $j$ at national level,

k - number of activities affected by the crisis.

The level of the vulnerability index is interpreted as follows: supra-unit values indicate the regions likely to be severely affected by the crisis, with a higher degree of risk than the national average; on the contrary, sub-unit values correspond to regional economies with below-average risk. The higher the value of the indicator, the more exposed the region is to the economic risks posed by the COVID-19 crisis.

A similar approach, based on mixing the economic structure with the reduced operational level of sectors (measured based on current employment) was used by Niembro and Calá (2020) for building an index of territorial economic impact of COVID-19 in Argentina. Our view is different in two aspects. Firstly, we use localisation coefficients instead of sectors' weights because they provide a better image on the relative importance of each economic activity in the economy of a region (Florence, 1939). Secondly, we adopt a forecasting perspective, more useful for decision makers, aiming to find which regions and counties are more vulnerable to the economic crisis generated by COVID-19 pandemic.
Aiming at a better understanding of the geographical distribution of the vulnerability index, we further tested the spatial dependence among its county level values. The standard method for identifying spatial autocorrelation is the Moran's I indicator, computed as follows (Anselin \& Rey, 1991):

$$
\mathrm{MI}=\frac{\mathrm{n} \sum_{i=1}^{n} \sum_{j=1}^{n} \mathrm{w}_{i j}\left(\mathrm{x}_{i}-\overline{\mathrm{x}}\right)\left(\mathrm{x}_{j}-\overline{\mathrm{x}}\right)}{\left(\sum_{i=1}^{n} \sum_{j=1}^{n} \mathrm{w}_{i j}\right) \sum_{i=1}^{n}\left(\mathrm{x}_{i}-\overline{\mathrm{x}}\right)^{2}}
$$

where:

$x_{i}, x_{j}$ - represent the vulnerability index in the counties $i$ and $j$ respectivelly,

$x \quad-$ is the average vulnerability index,

$w_{i j}$ - represent spatial weights capturing the "spatial influence" between county $j$ and county $i$.

The spatial matrix used in this paper is a first-order queen contiguity matrix, i.e. $w_{\mathrm{ij}}=1$ if regions $i$ and $j$ are neighbours and $w_{\mathrm{ij}}=0$ otherwise. Moran's / ranges from -1 (perfect dissimilarity among neighbours) to +1 (perfect similarity), while the null value corresponds to random spatial distribution of values. The permutation test will be further applied to validate the statistic significance of the Moran's I (Anselin \& Rey, 1991).

Since Moran's I is a global indicator of spatial autocorrelation, it is useful to measure the spatial association for each individual location $i$ as well. To this end we use the LISA (Local Indicators of Spatial Autocorrelation) indicator, defined as follows (Anselin, 2005; LeSage and Pace, 2009):

$$
\operatorname{LISA}_{i}=Z_{i} \sum_{j=1}^{m} w_{i j} Z_{j}
$$

where:

$z_{i}, z_{j}-$ are the standardized scores of SMEs density in the counties $i$ and $j$ respectively,

j - representing only the neighbors of county $i$ (as defined by the weights $w_{i j}$ ). 
The Cluster Map associated to the Local Indicators of Spatial Autocorrelation in Geoda points to significant cases of local spatial dependence by type of spatial correlation (positive-similar or negative-dissimilar).

Our empirical analysis draws on official statistics on economic activity at two territorial levels: county and region. The administrative-territorial structure in Romania consists of one regional level (counties or "judete" in Romanian, which correspond to the NUTS3 level of the EUROSTAT - 41 counties plus Bucharest Municipality) and one local level (cities, towns, communes). There are also eight development regions corresponding to the NUTS2 level, as territorial, but not administrative units. They were established in 1998 on a voluntary basis so as to ensure the framework for regional development policy elaboration and implementation, in accordance with the EU requirements. Each development region contains between 4 and 7 counties (except for Bucharest-Ilfov region, which consists only of Bucharest Municipality and IIfov County).

\section{Results - analysis and interpretation}

The COVID-19 crisis has several dimensions: a medical dimension, a social dimension and an economic dimension, all with an uneven territorial distribution. The biggest territorial differences are those related to the geographical distribution of the number of cases. In particular, the distribution of the number of COVID-19 cases by county shows a very pronounced variation (Crețan \& Light, 2020). The spread of the disease was accelerated by the relatively large number of Romanian transnational migrants returning home when the lockdown measures affected their employment abroad (Crețan \& Light, 2020). Since they are unevenly distributed geographically, the return migrants added to the territorial differences in COVID-19 incidence and effects. In addition, the optimism bias of the general population, empirically identified in the specific context of the current pandemic (Druica et al., 2020) hindered the effective enforcement of prevention measures in Romania.

However, the economic component of the COVID-19 crisis is not influenced by the geographical distribution of the number of cases because prevention measures such as social distancing, closure of non-essential activities, etc., have been implemented in the same way throughout the country. Therefore, the local economic effects depend more on the share in each territorial unit of the activities strongly affected by the measures imposed by the emergency ordinances, such as: hotels and restaurants, transportation, manufacturing and retail. The international literature previously reviewed points out that the same standpoint is shared by research studies undertaken in UK, Austria, Argentina, etc. (Kitsos, 2020a; Kitsos, 2020b; Bachtrögler et al., 2020; Niembro \& Calá, 2020).

At the beginning of the COVID-19 crisis, Romania was on an upward economic trajectory, the forecast being for continued sustained economic growth (NCSF, 2020). However, certain activities were shrinking and it is necessary to keep in mind that regardless of the effects of the current pandemic on the Romanian economy, there was already a declining trend in industrial production (NCSF, 2020): - 2.6\% between January and February 2020, compared to the same period in 2019. The largest decreases were recorded in the light industry, machine manufacturing and the metallurgical industry.

Our analysis on the regional economic effects of the COVID-19 crisis starts from the forecast provided by the NCSF in the aforementioned report (NCSF, 2020). Considering two probable scenarios, the $\mathrm{V}$-shaped one (a sharp decrease, then the recovery) and the L-shaped one (a fall followed by a prolonged recession, a delayed recovery) and taking into account previous experiences with like pandemics, the authors of the forecast chose an intermediate variant.

Thus, according to the study's authors, the recovery of the economic contraction is expected to occur in the last quarter of this year. It is important to consider 
the high degree of uncertainty associated with these estimates made under atypical circumstances, under the influence of factors with increased volatility, in a new context:

"The economic impact depends on factors that interact in a way that is difficult to estimate, including the trajectory of the pandemic, the intensity and effectiveness of protection measures, disruptions in supply chains, the impact of worsening conditions on global financial markets, changes in consumer behaviour, effects on confidence and the evolution of commodity prices." (NCSF, 2020: 11-12).

According to the estimates of the NCSF, the contraction of the activities hardest hit by the short-term COVID-19 crisis (spring 2020), in descending order of the severity degree, is expected to occur as follows: Hotels and restaurants: -45.8\%; Transportation: $-32.3 \%$; Manufacturing industry: $-17.7 \%$; Performing, cultural and recreational activities, other services: $-11.2 \%$; Real estate transactions: $-9 \%$; Construction: $-7 \%$; Retail trade: $-7.7 \%$.

The localisation coefficients have been computed for all activities, at county and development region level, for the latest available year - 2018 (Tab. 1, 2). The significant spatial polarisation illustrated by these data is an indication of differences in the level of specialisation of counties and inequalities in territorial distribution of economic activities. The differences are larger at county level than at regional level, the aggregate values partially hiding the inequalities of the component parts.

Next, we combined the level of dependence of a territorial unit's economy on the activities most affected by the crisis, as measured by location coefficients, with the information provided by the NCSF on the likely shortterm contraction of these activities. Basically, we calculate a weighted average of the localisation coefficients for the activities strongly affected by the crisis (hotels and restaurants, transportation, manufacturing and retail), using as weights the NCSF estimates on their short-term decline. These weights express the gravity of the evolution of the respective activities in the short term, and the average of the localisation coefficients thus weighted is an estimate of the degree of vulnerability of the territorial units to the current crisis. Although the calculations of location coefficients are confined in time by the available official statistics, the most recent data being for 2018, the results are little affected by the impossibility of updating the data, given that the changes in the territorial distribution of economic activities were very small.

Mapping of the vulnerability index (Fig. 1) reveals high discrepancies between the resilient counties displayed in darker shades (the darker the colour, the higher the resilience to the current COVID-19 induced economic crisis) and the sensitive counties displayed in light shades (the lighter the colour, the higher the vulnerability). The territorial distribution of the two categories - vulnerable and resilient - forms big clusters that largely correlate to the regional development level, with the less developed counties in Eastern and Southern part of Romania affected in a much lower degree. It seems that underdeveloped counties are better protected from the negative effects of economic shocks, as already revealed by the empirical research devoted to the previous global economic crisis (Goschin \& Constantin, 2010). The Moran's I indicator computed for the vulnerability index and the associated randomisation test shows that it has significant spatial autocorrelation, meaning that neighbouring counties tend to be alike in their sensitivity to crisis, generating large clusters of high or low resilience. The local indicators of spatial association (LISA) support this finding and point to a cluster of high vulnerability in the Center region and two strong clusters of resilience in South and East.

Our results regarding the vulnerability to crisis of Romania's regional economy display quite similar patterns with those described by Kitsos (2020b) for United Kingdom or Niembro and Calá (2020) for Argentina. A substantially different situation is revealed in the case of Austrian regions, where, despite the considerable differences 
Table 1. Economic vulnerability to the COVID-19 crisis on the short term for the Romanian counties

\begin{tabular}{|c|c|c|c|c|c|c|c|c|}
\hline \multirow[b]{2}{*}{ County } & \multicolumn{7}{|c|}{ Localisation coefficient } & \multirow[b]{2}{*}{$\begin{array}{l}\text { Vulner } \\
\text { ability } \\
\text { index }\end{array}$} \\
\hline & 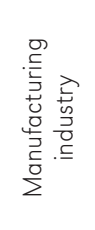 & 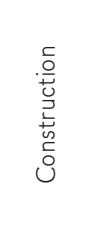 & 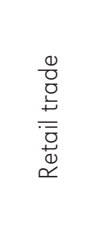 & 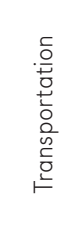 & 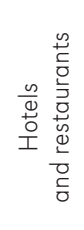 & 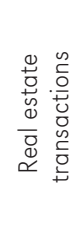 & 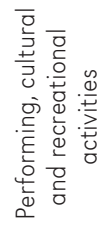 & \\
\hline Braşov & 1.299 & 1.288 & 1.085 & 1.063 & 1.775 & 1.460 & 1.085 & 1.395 \\
\hline Constanța & 0.676 & 1.488 & 1.176 & 1.645 & 1.564 & 1.320 & 0.981 & 1.374 \\
\hline Bucharest Municipality & 0.464 & 1.470 & 1.271 & 1.003 & 1.317 & 1.877 & 2.386 & 1.261 \\
\hline Ilfov & 1.065 & 0.720 & 1.475 & 1.438 & 1.053 & 2.377 & 1.085 & 1.247 \\
\hline Sibiu & 1.657 & 0.875 & 0.875 & 1.140 & 1.195 & 0.909 & 1.286 & 1.196 \\
\hline Cluj & 0.972 & 1.025 & 1.059 & 1.181 & 1.101 & 0.970 & 1.172 & 1.094 \\
\hline Covasna & 1.423 & 0.643 & 0.965 & 0.890 & 1.327 & 0.608 & 0.878 & 1.091 \\
\hline Prahova & 1.274 & 1.186 & 1.007 & 1.139 & 0.944 & 1.316 & 0.869 & 1.070 \\
\hline Bihor & 1.253 & 0.772 & 0.948 & 1.154 & 1.089 & 0.766 & 0.869 & 1.061 \\
\hline Vâlcea & 1.012 & 0.995 & 1.041 & 0.878 & 1.161 & 1.619 & 0.534 & 1.035 \\
\hline Arad & 1.609 & 0.798 & 1.013 & 1.200 & 0.812 & 0.829 & 0.733 & 1.017 \\
\hline Caraș-Severin & 1.010 & 0.858 & 0.789 & 1.089 & 1.095 & 0.727 & 0.700 & 0.994 \\
\hline Bistrița-Năsăud & 1.295 & 1.162 & 0.879 & 1.100 & 0.999 & 0.200 & 0.744 & 0.989 \\
\hline Timiş & 1.392 & 0.610 & 1.000 & 1.054 & 0.850 & 1.147 & 0.858 & 0.988 \\
\hline Mureș & 1.147 & 0.809 & 1.026 & 0.994 & 0.974 & 0.877 & 0.950 & 0.988 \\
\hline Galați & 0.803 & 1.126 & 0.969 & 0.932 & 1.007 & 1.123 & 1.043 & 0.977 \\
\hline Harghita & 1.236 & 0.782 & 1.012 & 0.844 & 1.210 & 0.388 & 0.480 & 0.974 \\
\hline Alba & 1.532 & 0.674 & 0.910 & 1.121 & 0.912 & 0.462 & 0.508 & 0.968 \\
\hline Argeș & 1.549 & 0.980 & 0.756 & 0.995 & 0.714 & 0.897 & 0.946 & 0.941 \\
\hline Brăila & 1.058 & 1.428 & 0.912 & 0.741 & 0.958 & 0.847 & 0.875 & 0.926 \\
\hline Hunedoara & 1.138 & 0.924 & 1.212 & 0.826 & 1.008 & 0.451 & 0.559 & 0.913 \\
\hline Dâmbovița & 1.272 & 0.434 & 1.006 & 1.290 & 0.742 & 0.544 & 0.505 & 0.911 \\
\hline Satu Mare & 1.204 & 1.061 & 0.877 & 0.889 & 0.766 & 1.053 & 0.797 & 0.898 \\
\hline laşi & 0.755 & 1.101 & 0.878 & 0.765 & 0.991 & 0.958 & 0.935 & 0.897 \\
\hline Tulcea & 0.871 & 0.871 & 0.865 & 0.858 & 1.134 & 0.316 & 0.522 & 0.896 \\
\hline Maramureș & 1.349 & 0.773 & 0.828 & 0.901 & 0.843 & 0.644 & 0.585 & 0.885 \\
\hline Neamț & 0.932 & 0.690 & 1.038 & 0.867 & 0.992 & 0.723 & 0.537 & 0.884 \\
\hline Suceava & 0.820 & 0.672 & 0.968 & 0.935 & 0.994 & 0.456 & 0.611 & 0.870 \\
\hline Sălaj & 1.296 & 0.742 & 0.882 & 1.076 & 0.797 & 0.256 & 0.422 & 0.865 \\
\hline Gorj & 0.629 & 1.554 & 0.856 & 0.852 & 0.931 & 0.578 & 0.716 & 0.858 \\
\hline Dolj & 0.749 & 0.844 & 1.001 & 0.790 & 0.808 & 1.117 & 0.880 & 0.836 \\
\hline Mehedinți & 0.828 & 1.234 & 0.700 & 0.840 & 0.856 & 0.261 & 0.540 & 0.793 \\
\hline Buzău & 1.051 & 0.549 & 0.937 & 0.853 & 0.760 & 0.629 & 0.454 & 0.785 \\
\hline Bacău & 0.925 & 1.623 & 0.998 & 0.690 & 0.646 & 0.878 & 0.622 & 0.779 \\
\hline Ialomița & 0.692 & 0.907 & 0.948 & 0.830 & 0.796 & 0.567 & 0.468 & 0.762 \\
\hline Vrancea & 0.981 & 0.925 & 0.784 & 0.808 & 0.718 & 0.576 & 0.475 & 0.759 \\
\hline Botoşani & 0.830 & 0.531 & 0.815 & 0.702 & 0.767 & 0.379 & 0.547 & 0.705 \\
\hline Giurgiu & 0.397 & 1.286 & 0.635 & 1.282 & 0.344 & 0.630 & 0.650 & 0.689 \\
\hline Călărași & 0.763 & 0.721 & 0.730 & 0.821 & 0.538 & 0.575 & 0.712 & 0.674 \\
\hline Olt & 1.077 & 0.795 & 0.638 & 0.695 & 0.411 & 0.165 & 0.545 & 0.596 \\
\hline Vaslui & 0.843 & 0.540 & 0.724 & 0.798 & 0.380 & 0.407 & 0.503 & 0.583 \\
\hline Teleorman & 0.739 & 0.390 & 0.798 & 0.715 & 0.413 & 0.378 & 0.312 & 0.539 \\
\hline
\end{tabular}




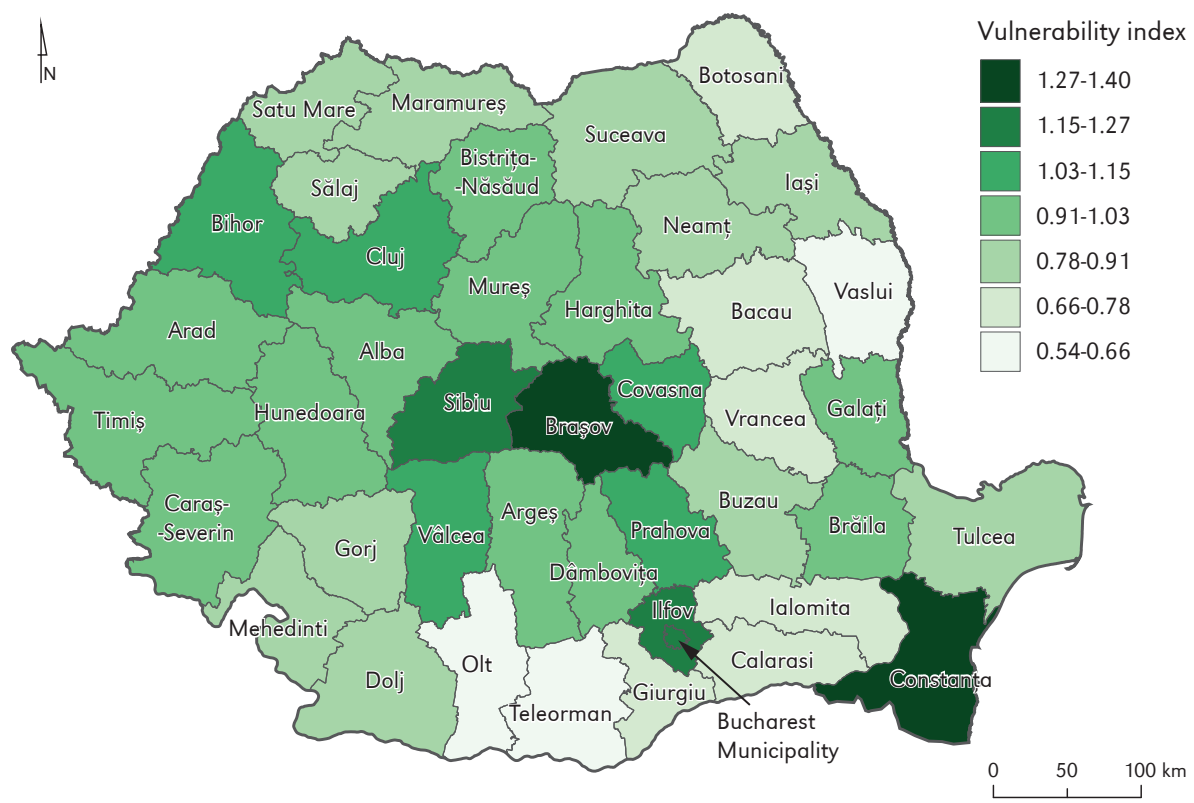

Figure 1. Romanian counties' economic vulnerability to the COVID-19 crisis on the short term

Source: Authors' processing and representation using QGIS

in economic specialisation, the vulnerability variation between regions is quite low given the fact that in all regions almost two thirds of the employment are recorded in strongly and very strongly affected sectors (Bachtrögler et al., 2020).

The values of the crisis vulnerability index (Tab. 1, last column and Fig. 1) show that the counties of Brașov and Constanța are the most affected, first of all due to the high share of tourism in the economy of each of these two counties. In the context of current crisis, additional risk factors are, in descending order of severity: transportation, construction and real estate transactions for Constanța County and real estate transactions, manufacturing and construction in the case of Brașov County. The Municipality of Bucharest (entertainment, cultural and recreational activities, real estate transactions, hotels and restaurants, construction, trade), as well as the counties of Ilfov (real estate transactions, trade and transport) and Sibiu (manufacturing industry, performance, cultural and recreational activities, real estate transactions, hotels and restaurants) are coming closer. The counties of Cluj, Covasna, Prahova, Bihor, Vâlcea and Arad have a comparatively lower degree of vulnerability, slightly above the national average. At the opposite pole, with a level of vulnerability of approximately 30\% below average, are the counties of Botoșani, Giurgiu, Călărasi, Olt and Vaslui, in whose economies the activities strongly affected by crisis have a smaller share than in the other counties.

In the case of development regions (Tab. 2), the most vulnerable is the Bucharest- Ilfov region, which brings together the weaknesses of Bucharest Municipality and Ilfov County in terms of the large share of activities affected by the crisis: performance, cultural and recreational activities, real estate transactions, hotels and restaurants, construction, trade and transportation. The Center region is particularly weakened by the scale of the manufacturing industry and the activities of hotels and restaurants, while 
Table 2. The level of economic vulnerability to the COVID-19 crisis in the short term for the Romanian development regions

\begin{tabular}{|c|c|c|c|c|c|c|c|c|}
\hline \multirow[b]{2}{*}{ Region } & \multicolumn{7}{|c|}{ Localisation coefficient } & \multirow[b]{2}{*}{$\begin{array}{l}\text { Vulner- } \\
\text { ability } \\
\text { index }\end{array}$} \\
\hline & 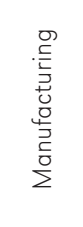 & 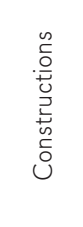 & 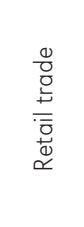 & 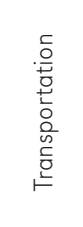 & 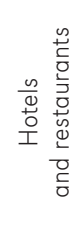 & 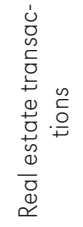 & 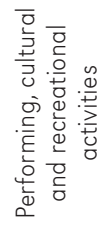 & \\
\hline Bucharest-IIfov & 0.551 & 1.360 & 1.300 & 1.066 & 1.279 & 1.950 & 2.196 & 1.259 \\
\hline Centru & 1.369 & 0.901 & 0.988 & 1.031 & 1.257 & 0.880 & 0.913 & 1.129 \\
\hline Sud-Est & 0.868 & 1.126 & 0.984 & 1.085 & 1.097 & 0.922 & 0.783 & 1.021 \\
\hline Nord-Vest & 1.185 & 0.923 & 0.941 & 1.077 & 0.980 & 0.741 & 0.856 & 0.999 \\
\hline Vest & 1.349 & 0.752 & 1.020 & 1.050 & 0.903 & 0.874 & 0.747 & 0.981 \\
\hline Sud-Muntenia & 1.123 & 0.868 & 0.872 & 1.042 & 0.708 & 0.813 & 0.699 & 0.868 \\
\hline Sud-Vest Oltenia & 0.855 & 1.031 & 0.877 & 0.805 & 0.827 & 0.836 & 0.677 & 0.827 \\
\hline Nord-Est & 0.843 & 0.920 & 0.917 & 0.796 & 0.839 & 0.684 & 0.664 & 0.813 \\
\hline
\end{tabular}

the South-East region is affected by the location of construction activities, hotels and restaurants and transportation. Vulnerability coefficients slightly below 1 characterize the North-West region (manufacturing and transportation) and West region (in this case manufacturing industry is the strongest risk factor). The North-East region is the least vulnerable.

Efforts to counteract the emerging economic crisis are going on several levels. An important role is played by well-founded, transparent and objective government measures to support the business environment in its efforts to recover economic activity. An example is the implementattion of the SME Invest Romania Programme with regard to guaranteed loans. These funds are intended for small entrepreneurs, who are the most vulnerable to the current economic crisis.

Given the uneven territorial manifestation of the crisis, the local efforts and initiatives are as important as the governmental measures, and in Romania numerous local actions have been initiated that prove the capacity to adapt quickly. A common case is the conversion of various factories' production to masks and biocides, and even the attempts to produce ventilators. For example, the national armament company Roman makes surgical masks. Owners of agrotourism pensions in Maramureș have refocused on the preparation and delivery of food products, based on orders on a social network where they formed a group of small local producers. The solutions of this crisis are also outlined from the perspective of the transformations that the economy and society are currently undergoing, so that the necessary adjustments support future growth and the present disruptive effects can be transformed into economic opportunities in the future.

As regards the development models, the variation of the economic impact of the COVID-19 crisis from one economic sector to another, from one region to another and even from one company to another determines the need to rethink, find answers to the actions of factors such as "exposure to China as a source of intermediate inputs, the possibility of resorting to alternative suppliers, the existence of stocks or the dependence on 'just in time' production processes" (EC, 2020). Thus, the view that supports the reconsideration of current development models based on global production networks in favour of 'classic' models such as local production systems, with a high 
degree of integration at national level and, at the next level, at European level is more and more discussed. This will result in 'economic restructuring' measures combined with 'spatial restructuring' measures, leading to rationally designed economic systems, able to ensure a lower vulnerability to global shocks. As a consequence, at regional level 'place-based' and 'place-sensitive' policies will represent a major orientation (Ortega-Argilés, 2020).

An effective response to the crisis also depends on the robustness of vertical and horizontal coordination mechanisms. International experience shows that coordinated action at all levels of government (central and local) can minimize crisis management failures. Dissociated measures can generate collective risks. Beyond the option for centralisation or decentralisation, what matters is the efficiency of coordination mechanisms and the ability of government actors to align priorities, implement common responses, support each other and encourage the exchange of information. In fact, while some governments temporarily recentralise health management in response to the crisis, such as Norway and Switzerland, others, such as the United Kingdom, decentralise it (OECD, 2020).

Last but not least, accessing EU financial support mechanisms and using common solutions that are emerging at EU level can provide the essential financial resources to stimulate economic recovery and to quickly overcome the crisis. For example, the implementation of the SURE (Support to mitigate Unemployment Risks in an Emergency) initiative and the establishment of the EU Recovery and Resilience Facility are strong guarantees for the success of EU countries' economic recovery efforts.

\section{Concluding remarks}

Our research started from the finding that the regional distribution of infection cases, and especially the economic implications of social distancing measures taken in the context of emergency ordinances, shows great regional variation. Even areas with low incidence of disease have been severely affected by the economic activity declining, especially if sectors such as hotels and restaurants, transportation, manufacturing or trade have a high share in the local economy. As in the case of "classic" crises, the economic shock caused by the pandemic seems to be closely linked to the sectoral structure of local economies, the source of the problems not being specialisation itself, but the high dependence on sectors of activity directly affected by measures for mitigating the epidemic impact, such as travel restrictions, temporary closure of nonessential activities, etc. From this viewpoint our conclusion has the same basis as the one expressed by Bachtrögler et al. (2020) in the case of the Austrian regions, and we also support the proposal of policy measures with broad sectoral impact adapted to each regional context as a way to ensure an optimal effect.

An effective response to the crisis obviously starts from the governmental level, through well-founded, transparent and objective measures such as the implementation of the SME (Small and medium-sized enterprises) Invest Romania Programme on guaranteed loans for small entrepreneurs, who are the most vulnerable to the current economic crisis. In addition, local efforts and initiatives that are essential for rapid adaptation to the new economic reality need to be stimulated. Adjustments imposed by the current challenges of the crisis can support future growth, and the current disruptive effects can be turned into economic opportunities, stimulated by combined economic and spatial restructuring processes. An effective response to the crisis also depends on the robustness of vertical and horizontal coordination mechanisms, with international experience showing that coordinated actions at all levels of government (central and local) can minimize crisis management failures. The solutions proposed by the EU, based on solid financial support mechanisms, can also play a very important 
role in the efforts aiming at crisis overcoming and economic recovery.

The limitations of this study come primarily from the lack of more recent data on the situation of regional economies. As imposed by the objective situation at global scale, the studies undertaken up to now in the international arena have analysed the economic impact of the first pandemic wave, followed by the first manifestations after the lockdown was ended. In line with this orientation, our research has concentrated on the first wave. Another important limitation comes from the uncertainty of the estimates provided by NCSF regarding the size of the shortterm contraction at the economic activity level. These estimates were used in the paper to determine the crisis vulnerability index for regions and counties, and the revised forecast to be published in the next months could show significant differences from current values, changing the image of the crisis distribution in the territory.

Moreover, as pointed out by Gong et al. (2020) the pandemic crisis consists of several successive sub-shocks, so that after the lockdown shock the shrinkage resulted from the declining demand will be focused on. Hence, the research is still developing. As the pandemic is characterised by fast-changing circumstances, the current study has to adapt to an unstable reality, which can go to unpredicted directions. The rapid update of statistical data is a pre-requisite for our endeavours to develop subsequent research versions, able to contribute to a significant dialogue and to supporting the decision-makers responsible for provision of appropriate responses to the challenges generated by the COVID-19 pandemic.

Finally, we stress the idea expressed by the ERDB (2020b) that the tremendous uncertainty that characterises the COVID-19 crisis makes all projections be subject to large revisions, in particular in developing economies and emerging markets, which will require frequent revisions of all provided forecasts.

\section{Acknowledgements}

This work was partially supported by a grant of the Romanian Ministry of Research and Innovation, CNCS - UEFISCDI, project number PN-III-P4-ID-PCCF-2016-0166: "ReGrowEU Advancing ground-breaking research in regional growth and development theories, through a resilience approach: towards a convergent, balanced and sustainable European Union".

\section{Editors' note:}

Unless otherwise stated, the sources of tables and figures are the authors', on the basis of their own research.

\section{References}

AISR. (2020). The Italian Section of Regional Science is calling for contributions on COVID-19 and territorial impact. ERSA. https://ersa.org/2020/04/20/aisre-special-call-on-covid-19/

Anselin, L. (2005). Exploring Spatial Data with GeoDaTM.

A Workbook. Urbana: Spatial Analysis Laboratory Department of Geography, University of Illinois. https://www.geos.ed.ac.uk/ gisteac/fspat/geodaworkbook.pdf

Anselin, L., Rey, S. (1991). Properties of tests for spatial dependence in linear regression models. Geographical Analysis, 23, 112-131.

Bachtrögler, J., Firgo, M., Fritz, O., Klien, M., Mayerhofer, P., Piribauer, P., Streicher, G. (2020). Regional differences in the economic vulnerability to the current COVID-19 crisis in Austria. WIFO Working Paper. https://ersa.org/wp-content/uploads/2020/04/WIFO_Regional-differences_economic-vulnerability_Austria.pdf 
Bailey, D., Clark, J., Colombelli, A., Corradini, C., De Propris, L., Derudder, B., Fratesi, U., Fritsch, M., Harrison, J., Hatfield, M., Kemeny, T., Kogler, D.F., Lagendijk, A., Lawton, P., Ortega-Argilés, R., Iglesias Otero, C., Usai, S. (2020). Regions in a time of pandemic. Regional Studies, 54 (9), 1163-1174. https://doi.org/10.1080/00343404.2020.1798611

Benet, V. (2020). Spending to counteract coronavirus creates to "tilt to green". https://www.ebrd.com/news/2020/spending-to-counteract-coronavirus-creates-chance-to-tilt-to-green-html

Boumahdi, I., Zaoujal, N., Fadlallah, A. (2020). Differentiated territorial effect of COVID-19 on the tourism sector in Morocco. RSPP Working Paper, No 2020.001 - Special Series on COVID-19. https://www.regionalscience.org/images/PDF/WP/RSPPworkingpaper.2020.001.pdf

Crețan, R., Light, D. (2020). COVID-19 in Romania: Transnational labour, geopolitics, and the Roma 'outsiders'. Eurasian Geography and Economics, 61(4), 559-572. https://doi.org/10.1080/15387216.2020.1780929

Cuadrado-Roura, J.R., Maroto, A. (2016). Unbalanced regional resilience to the economic crisis in Spain: a tale of specialisation and productivity. Cambridge Journal of Regions, Economy and Society, 9(1), 153-178. https://doi.org/10.1093/cjres/rsv034

Dabson, B., Heflin, C., Miller, K. (2012). Regional Resilience. Research and Policy Brief. RUPRI-Rural Futures Lab, Harry S Truman School of Public Affairs, University of Missouri. Retrieved from https://www.nado.org/wp-content/uploads/2012/04/RUPRI-Regional-Resilience-Research-Policy-Brief.pdf [8 July 2020].

De Groot, S.P.T., Mohlmann, J.L., Garretsen, J.H., De Groot, H.L.F. (2011). The crisis sensitivity of European countries and regions: Stylized facts and spatial heterogeneity. Cambridge Journal of Regions, Economy and Society, 4(3), 437-456. https://doi.org/10.1093/cjres/rsr024

De Propris, L., Bailey, D. (2020). Industry 4.0 and regional transformations. London: Routledge. https://doi.org/10.4324/9780429057984

Druică, E., Musso, F., lanole-Călin, R. (2020). Optimism bias during the COVID-19 pandemic: Empirical evidence from Romania and Italy. Games, 11(3), 39. https://doi.org/10.3390/g11030039

EC. (2020). Jobs and economy during coronavirus pandemic. European Commission. https://ec.europa.eu/info/live-work-travel-eu/health/coronavirus-response/jobs-and-economy-duringcoronavirus-pandemic_ro

EBRD. (2020a). From shock to recovery. Regional economic prospects. European Bank for Reconstruction and Development. https://www.ebrd.com/what-we-do/economic-research-and-data/rep.html

EBRD. (2020b). COVID-19: Early estimates of the damage, uncertain prospects - September 2020 - Output in the EBRD regions. European Bank for Reconstruction and Development. https://www.ebrd.com/what-we-do/economic-research-and-data/rep.html

Florence, P. (1939). Report of the location of industry. Political and Economic Planning. London.

Gallopín, G.C. (2006). Linkages among vulnerability, resilience, and adaptive capacity. Global Environmental Change, 16(3), 293-303. https://doi.org/10.1016/j.gloenvcha.2006.02.004

Gombos, K., Herczeg, R., Eross, B., Kovacs, S.Z., Kiss, S., Szakacs, Z., Imrei, M., Szentesi, A., Nagy, A., Fabian, A., Hegyi, P., Gyensesi, A. (2020). Translating scientific knowledge to government decision makers has crucial importance in the management of the COVID-19 pandemic. Population and Health Management (published online: 2 September 2020). https://doi.org/10.1089/pop.2020.0159

Gong, H., Hassink, R., Tan, J., Huang, D. (2020). Regional resilience in times of a pandemic crisis: The case of COVID-19 in China. Tijdschrift voor economische en sociale geografie (published online: 19 June 2020). https://doi.org/10.1111/tesg.12447

Goschin, Z., Constantin, D.L. (2010). The geography of the financial crisis and policy response in Romania. In G. Gorzelak, Ch. Goh (Eds.), Financial crisis in Central and Eastern Europe - from similarity to diversity (pp. 161-191). Warsaw: Barbara Budrich Publishers, Wydawnictwo Naukowe Scholar Publishing House. 
Hudec, O., Manakova, N., Šiserová, M. (2017). Which cities are vulnerable to the global economic crisis? Evidence related to Slovak cities. Theoretical and Empirical Researches in Urban Management, 12(2), 30-47. http://um.ase.ro/no122/3.pdf

Irving, J. (2020). Pandemic vulnerability index. https://www.regionalstudies.org/news/working-in-lockdown-during-the-covid-19-pandemic-is-an-opportunity-to-lend-our-expertise/

Ivanov, D., Dolgui, A. (2020). Viability of intertwined supply networks: Extending the supply chain resilience angles towards survivability. A position paper motivated by COVID-19 outbreak. International Journal of Production Research, 58(10), 2904-2915. https://doi.org/10.1080/00207543.2020.1750727

Kitsos, A. (2020a). Local resilience and the COVID-19 economic crisis. ERSA. https://ersa.org/wp-content/uploads/2020/04/COVID-19-KITSOS.pdf

Kitsos, A. (2020b). The uneven spatial footprint of the COVID-19 shutdown. ERSA. https://ersa.org/wp-content/uploads/2020/04/Blog_Resilience.pdf

KPMG. (2020). Chief economist's note: COVID-19's regional jigsaw. https://home.kpmg/uk/en/home/ insights/2020/05/chief-economist-note-new.html [20 July 2020]

Kydland, F., Prescott, E. (1982). Time to build and aggregate fluctuations. Econometrica, 50(6), 13451370. https://doi.org/10.2307/1913386

LeSage, J.P., Pace, R.K. (2009). Introduction to spatial econometrics. New York: Chapman and Hall/CRC. https://doi.org/10.1201/9781420064254

Mazza, P.I., Mavri, M. (2020). Is this the wright time to talk about Cloud Regions? The contribution of COVID-19 to concepts of Regional Development. ERSA. https://ersa.org/wp-content/uploads/2020/07/Note_MazzaMavri.pdf

McCoy, D. (2020). What exactly is the government's coronavirus strategy?. Queen Mary University of London. https://www.qmul.ac.uk/media/news/2020/pr/what-exactly-is-the-governments-coronavirus-strategy.html

NIS. (2020a). Civilian employment by activity at the NACE-2 level, by development region and by county. TEMPO Online, National Institute of Statistics. http://statistici.insse.ro:8077/tempo-online/\#/pages/tables/insse-table

NIS. (2020b). Evaluation of COVID-19 impact on the economic environment in March and April 2020, Press Release, No. 104 / April 15, 2020, National Institute of Statistics. https://insse.ro/cms/ro/content/cercetare-experimentală-evaluarea-impactului-covid-19-asupra-mediului-economic-în-lunile-0

Niembro, A., Calá, C.D. (2020). A first exploratory analysis of the regional economic impact of COVID-19 in Argentina. ERSA.

https://ersa.org/wp-content/uploads/2020/08/Niembro-Cala_Regional-Impact-of-COVID19-in-Argentina.pdf

NCSF. (2020). The current context of the Romanian economy and the impact of coronavirus on the main macroeconomic indicators. National Commission for Strategy and Forecasting. http://www.cnp.ro/user/repository/prognoze/Contextul_actual_al_economiei_romanesti_si_impactul_coronavirusului_asupra_principalilor_indicatori_macroeconomici.pdf

OECD. (2020). The territorial impact of COVID-19: managing the crisis across levels of government. https://read.oecd-ilibrary.org/view/?ref=128_128287-5agkkojaaa\&title=The-territorial-impact-of-covid19-managing-the-crisis-across-levels-of-government

Ortega-Argilés, R. (2020). Regions in a time of pandemic. ERSA. https://ersa.org/wp-content/ uploads/2020/09/WMREDI-Covid-19-Regions-in-time-of-pandemic-Ortega-Argiles-ERSA.pdf

Rebelo, S. (2005). Real business cycle models: Past, present and future. Northwestern University, NBER, and CEPR. https://www.kellogg.northwestern.edu/faculty/rebelo/htm/rbc.pdf

Seeliger, L., Turok, I. (2013). Towards sustainable cities: Extending resilience with insights from vulnerability and transition theory. Sustainability, 5(5), 2108-2128. https://doi.org/10.3390/su5052108

Stiglitz, J. (2020). We need a better balance between globalization and self-reliance. Foreign Policy: How the Economy Will Look After the Coronavirus Pandemic. https://foreignpolicy.com/2020/04/15/how-the-economy-will-look-after-the-coronavirus-pandemic/ 
UrbanizeHub. (2020). Ce orase din Romania vor fi cel mai putin afectate de criza post-COVID-19. UrbanizeHub - Politici urbane \& Guvernanta.

https://urbanizehub.ro/ce-orase-din-romania-vor-fi-cel-mai-putin-afectate-de-criza-post-covid-19/

Volintiru, C. (2020). Cum va arata economia dupa COVID-19. Dilema veche, 14-20 mai 2020. Retrieved from https://dilemaveche.ro/sectiune/tema-saptamanii/articol/cum-va-arata-economia-dupa-covid-19 [12 June 2020].

Williamson, E., Walker, A.J., Bhaskaran, K.J., Bacon, S., Bates, C., Morton, C.E., Cockburn, J. (2020). OpenSAFELY: Factors associated with COVID-19-related hospital death in the linked electronic health records of 17 million adult NHS patients. MedRxiv. https://doi.org/10.1101/2020.05.06.20092999

World Bank. (2020). Fighting COVID-19 (English). Europe and Central Asia economic update Washington D.C.: World Bank Group.

http://documents.worldbank.org/curated/en/276301586361664871/Fighting-COVID-19 